\title{
Comparison of the diagnostic yields of disposable and reusable cytology brushes in fibreoptic bronchoscopy
}

\author{
W J M Kinnear, M J Wilkinson, P D James, I D A Johnston
}

\begin{abstract}
Disposable rake and reusable bristle type cytology brushes have been compared in 50 patients undergoing fibreoptic bronchoscopy for suspected malignancy. Forty seven patients were eventually found to have carcinoma of the bronchus. A diagnosis of malignancy was made from the specimens taken with one or other brush in 34 patients, from the reusable brush in 28 , and from the disposable brush in 31 . The specimens taken with the two types of brush were of similar quality. The reusable brush is about five times less expensive per procedure but carries a risk of cross contamination and cross infection, and time is needed to clean the brush after each bronchoscopy. The diagnostic yield appears to be at least as good with the disposable brush.
\end{abstract}

Bronchial brush biopsy has been in use for several decades ${ }^{1}$ and is now used most commonly with the fibreoptic bronchoscope. ${ }^{2}$ Two main types of brush are available. The disposable rake type is enclosed in a plastic sheath, which is inserted through the bronchoscope. The brush is pushed out of the sheath to collect the specimen, and then withdrawn into the sheath before removal from the bronchoscope. The reusable bristle type is inserted unprotected through the bronchoscope. After specimens have been obtained, the reusable brush may be withdrawn through the bronchoscope, which is left in place for further procedures. Alternatively, the bronchoscope may be removed from the patient with the brush protruding from it, in which case cytology slides can be made from the brush without losing material on the inside of the bronchoscope channel. This was our usual practice as our impression was that the specimens obtained by this technique were superior to those obtained with the disposable brush. Time and care are necessary for cleaning the reusable brush to prevent cross contamination of specimens or transmission of infection. We therefore undertook a prospective comparison of the two types of brush.

\section{Methods}

We studied 50 patients (41 male; median age 67 , range $32-82$ years) undergoing bronchoscopy for suspected malignancy. Trap specimens were taken and biopsy specimens obtained if a visible lesion was seen. Brush specimens were then taken with both types of brush (disposable rake and reusable bristle, Olympus), in random order, from each patient.

Four cytology slides were made as soon as the brush was removed from the patient, with the reusable brush still protruding from the bronchoscope if it had been used second. Two experienced cytologists (MJW and PDJ) examined the slides without knowledge of which brush had been used to obtain the specimens. For each slide they assessed whether an adequate specimen for cytological examination had been obtained and whether malignant cells were present, and they stated a preference for one or other set of slides.

Statistical comparisons were made by using the $\chi^{2}$ test with Yates's correction.

\section{Results}

Carcinoma of the bronchus was the final diagnosis in 47 of the 50 patients. Thirty patients had macroscopic evidence of a tumour at bronchoscopy, and in a further 12 patients the appearances were suspicious but not diagnostic of malignancy. A pathological diagnosis of malignancy was made from the specimens taken at bronchoscopy in 37 patients. In two patients further investigation did not disclose any evidence of malignancy and one had a carcinoid tumour.

One or other brush provided a specimen that gave a positive diagnosis of malignancy in 34 patients, this being the only positive bronchoscopy specimen in seven. The cytologists found four sets of slides to contain inadequate material for cytological examination, two from each type of brush. They preferred the slides made from the disposable brush in 21 patients and from the reusable brush in 23 patients.

A diagnosis of malignancy was made with the disposable brush in $31(62 \%)$ of patients and with the reusable brush in $28(56 \%)(95 \%$

Table 1 Diagnostic yield with disposable and reusable types of cytology brush

\begin{tabular}{llll}
\hline & \multicolumn{2}{l}{ Reusable } & \\
\cline { 2 - 4 } & Positive & Negative & Total \\
\hline Disposable & & & \\
Positive & 25 & 6 & 31 \\
Negative & 3 & 16 & 19 \\
Total & 28 & 22 & 50 \\
\hline
\end{tabular}




\author{
Magnified view of \\ disposable rake (right) \\ and reusable bristle (left) \\ bronchoscopic cytology \\ brushes.
}

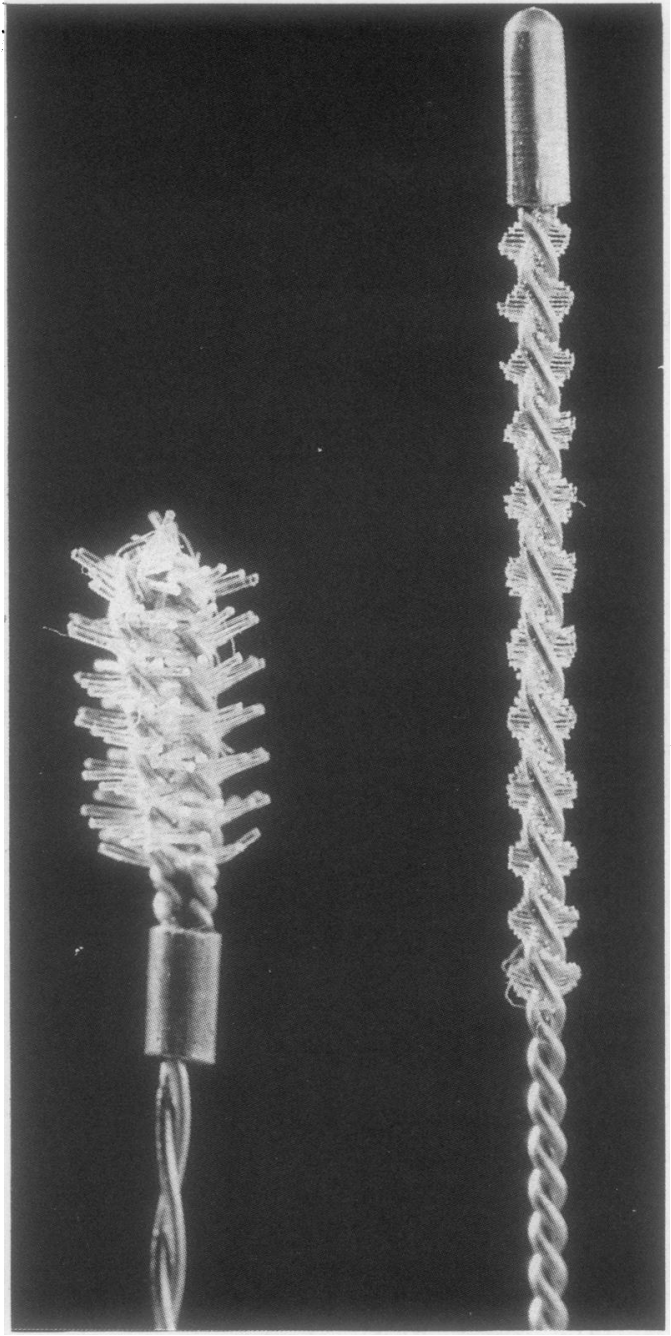

Table 2 Diagnostic yield of disposable and reusable cytology brushes by the order in which they were used

\begin{tabular}{llll}
\hline & First & Second & Total \\
\hline Disposable & & & \\
Positive & 19 & 12 & 31 \\
Negative & 25 & 25 & 50 \\
Reusable & & & \\
Positive & 12 & 16 & 28 \\
Negative & 25 & 25 & 50 \\
\hline
\end{tabular}

confidence interval for the $6 \%$ difference $-13 \%$ to $+25 \%$ )- see table 1 . In six patients the disposable brush gave a positive diagnosis whereas the reusable brush did not, and in three the opposite applied. In the 25 patients in whom the reusable brush was used second (table 2) a positive diagnosis was made in 16 $(32 \%)$, compared with $19(38 \%)$ with the disposable brush $(95 \%$ CI for this $6 \%$ difference $-20 \%$ to $+32 \%$ ).

\section{Discussion}

There have been many studies of the diagnostic yield of brushings at bronchoscopy (reviewed by Mak et al $^{3}$ ), but we are unaware of any formal comparisons of the types of brush available. The quality of specimens obtained and the diagnostic yield from the disposable brush were as good as those from the reusable brush, though the size of the study was not large enough to exclude a small but real difference between the two types of brush.

Our conclusion that the diagnostic yield from the disposable brush was equivalent to that obtained with the reusable brush contrasts with our previous impression that the reusable brush was superior, and holds good irrespective of whether or not the reusable brush was withdrawn through the bronchoscope before the cytology slides were made. Most of the patients in our study had central tumours, but we see no reason to suppose that our findings would not apply to peripheral lesions also.

We are unaware of any instances of cross contamination of specimens or transmission of infection with cytology brushes. Mycobacterium chelonei has, however, been isolated from brushes used with a bronchoscope later found to harbour the organism and thought to have been damaged by bent cytology brushes, presumably of the reusable type. ${ }^{4}$ It takes 10 30 minutes to clean the reusable brush properly, and our nursing staff therefore prefer the disposable type. The disposable brush costs about $f 10$. Each reusable brush costs slightly less than this and lasts for about 10 bronchoscopies. The introducer for the reusable brushes costs around $£ 100$ and lasts for about 100 procedures. Thus the cost of the reusable brush is about five times less per procedure than that of the disposable brush, though this does not take into account the cost of the nursing time needed for cleaning the brush. Since performing this study we have changed to the exclusive use of the disposable brush.

We would like to thank the nursing staff in our endoscopy unit for their expert assistance.

1 Esguerra A, Ramsby G. Transbronchial brush biopsyclinical indications. Am Rev Respir Dis 1969;100:403-5.

2 Stradling P. Diagnostic bronchoscopy. Edinburgh: Churchill Livingstone, 1986:138-9.

3 Mak VHF, Johnston IDA, Hetzel MR, Grubb C. Value of washings and brushings at fibreoptic bronchoscopy in the diagnosis of cancer. Thorax 1990;45:373-6.

4 Pappas SA, Schaaff DM, Dicostanzo MB, King FW, Sharp JT. Contamination of flexible fibreoptic bronchoscopes. Am Rev Respir Dis 1983;127:391-2. 